\title{
Hepatitis $C$ and not Hepatitis B virus is a risk factor for anti-tuberculosis drug induced liver injury
}

Wan Soo Kim', Sang Soo Lee ${ }^{1 *}$, Chang Min Lee ${ }^{1}$, Hong Jun Kim', Chang Yoon Ha', Hyun Jin Kim', Tae Hyo Kim', Woon Tae Jung ${ }^{1}$, Ok Jae Lee ${ }^{1}$, Jeong Woo Hong ${ }^{1}$, Hyun Seon You ${ }^{1}$ and Hyun Chin Cho ${ }^{2}$

\begin{abstract}
Background: The risk of anti-tuberculosis (TB) drug-induced liver injury (DILI) in patients with chronic viral hepatitis $(\mathrm{CVH})$ is not clear. The aim of this study was to investigate incidence and risk factors associated with TB DILI in CVH and non-CVH patients.

Methods: Retrospectively, a total of $128 \mathrm{CVH}$ patients who received anti-TB medication from January 2005 to February 2014 were reviewed. Among these, 83 patients had hepatitis B virus (HBV), 41 patients had hepatitis C virus ( $\mathrm{HCV}$ ) and 4 patients were dual hepatitis $B$ and hepatitis $\mathrm{C}$ virus co-infected ( $\mathrm{HBV}+\mathrm{HCV}$ ) with 251 non-CVH patients who received anti-TB medication selected as the controls. There were no human immunodeficiency virus co-infected patients. Risk factors for DILI were analyzed using cox regression analysis.

Results: The incidence of DILI was significantly higher in the HCV group $(13 / 41[31.7 \%], p<0.001)$ and HBV + HCV groups (3/4 [75.0\%], $p=0.002)$ compared to the control group (25/251 [10.0\%]). The incidence of transient liver function impairment in the hepatitis B virus group was higher than in the control group (18/83 [21.7 \%] vs. 27/251 [10.8\%] $p=0.010)$, but not in DILI (11/83 [13.3\%] vs. 25/251 [10.0\%], $p=0.400)$. In total patients, HCV, HBV + HCV co-infection, older age, and baseline liver function abnormality were independent factors of DILI.

Conclusions: It is recommended to carefully monitor for DILI in patients with HCV or HBV/HCV co-infection, older age, and baseline liver function abnormality.
\end{abstract}

Keywords: Tuberculosis, Treatment, Hepatitis B virus, Hepatitis C virus, Drug induced liver injury

\section{Background}

Standard anti-tuberculosis (TB) drugs, including isoniazid (INH), rifampin (RFP), ethambutol (EMB), and pyrazinamide (PZA) are highly effective in treating TB. However, drug induced liver injury (DILI) associated with anti-TB treatment is the most important adverse event, which results in a low treatment success rate [1]. The incidence of DILI during standard anti-TB treatment ranges from $2 \%$ to $28 \%$ [2-6]. Once DILI occurs, all anti-TB drugs should be withheld until a complete resolution of the hepatotoxicity is accomplished [7].

\footnotetext{
* Correspondence: 3939lee@naver.com

'Department of Internal Medicine, Gyeongsang National University Hospital, Gyeongsang National University School of Medicine, Gangnam-ro 79, Jinju, Gyeognam 660-702, South Korea

Full list of author information is available at the end of the article
}

Advanced age, female gender, alcohol abuse, malnutrition, and underlying chronic liver disease have been reported to be significant risk factors for DILI during antiTB treatment [8-10]. However, it remains unclear whether the incidence of DILI increases during anti-TB treatment in patients with chronic viral hepatitis $(\mathrm{CVH})$. In a previous Hong Kong study [11], persistent liver dysfunction was shown to be more common in hepatitis B virus $(\mathrm{HBV})$ infected patients. In addition, several recent studies have suggested that HCV infections are also a significant risk factor for incident DILI during anti-TB treatment [12-15]. However, in still other studies, the incidence of transient liver dysfunction during anti-TB treatment was found to be higher in HBV or HCV infected patients than in patients without viral hepatitis, 
but the incidence of DILI was not different between $\mathrm{CVH}$ and non-CVH patients [16-20].

In Korea, both $\mathrm{TB}$ and $\mathrm{CVH}$ are major public health concerns. The number of new onset TB patients is about 40,000 per year in Korea and is continuing to increase [21]. The prevalence of HBV in Korean population is $3.7 \%$ [22], and $0.78 \%$ of the Korean population has an $\mathrm{HCV}$ infection [23]. The aim of present study was investigate the incidence and risk factors of DILI in patients with $\mathrm{CVH}$ and to compare them to patients without $\mathrm{CVH}$.

\section{Materials and Methods}

\section{Study populations}

We retrospectively enrolled a total of 128 patients with $\mathrm{CVH}$ who were consecutively diagnosed with pulmonary or extrapulmonary $\mathrm{TB}$ and receiving standard anti-TB drugs at the Gyeongsang National University Hospital, a tertiary hospital in Korea, from January 2005 to February 2014. Among these, 83 patients were positive for HBV surface antigen (HBsAg) and negative for the HCV antibody (HBV group), 41 were negative for $\mathrm{HBsAg}$ and positive for the $\mathrm{HCV}$ antibody (HCV group), and 4 were positive for both $\mathrm{HBsAg}$ and $\mathrm{HCV}$ antibody $(\mathrm{HBV}+$ HCV group). The following data were collected from electronic medical records by computer-assisted chart review; age, sex, alcohol ingestion, body mass index (BMI), previous TB history, TB infection site (lung or other), date of anti-TB drugs prescription, regimen of anti-TB drugs, HBsAg, HCV antibodies, HBV DNA, HCV RNA, serial liver function test once in 2 weeks, including aspartate aminotransferase (AST), alanine aminotransferase (ALT), and total bilirubin, symptoms of hepatitis including anorexia, nausea, vomiting, generalized weakness, abdominal discomfort, and jaundice, and comorbidities including liver cirrhosis, chronic kidney disease, diabetes mellitus, hepatocecullar carcinoma, and other malignancies.

For the purposes of comparison, 251 consecutively patients diagnosed with pulmonary or extrapulmonary $\mathrm{TB}$ with negative HBsAg and HCV antibody from January 2013 to February 2014 were enrolled and their respective electronic medical records were analyzed as the control group. If a patient had liver function impairment, the time until onset was measured in days. The mean onset time and standard deviation were calculated. The incidence of DILI was investigated according to patients with and without viral hepatitis. Follow up duration was measured by 12 months in cases without hepatotoxicity. Patients with initial AST or ALT over 2 times the upper limit of normal, initial total bilirubin over 1.5 times the upper limit of normal, less than 3 months of treatment duration, and liver function abnormality caused by a source other than anti-TB drugs were excluded. There were no HIV-infected patients among the enrolled patients. The present study was approved by the Institutional Review Board of the Gyeongsang National University Hospital.

\section{Definitions}

The liver function impairment was classified as transient liver function impairment (TLI) and DILI. The definition of TLI and DILI was based on previous studies and literature [1, 16-18, 24]. TLI was defined as AST/ALT levels above the upper limit of normal (40 IU/L), but were still less than three times the upper limit of normal $(120 \mathrm{IU} / \mathrm{L})$ and resolved spontaneously, despite continued medication. DILI was defined as liver transaminase levels were exceeded $120 \mathrm{IU} / \mathrm{L}$ with symptoms of hepatitis or exceeded $200 \mathrm{IU} / \mathrm{L}$ without symptoms. If AST/ ALT levels were under $200 \mathrm{IU} / \mathrm{L}$, the case was defined as mild DILI. AST/ALT levels of 200 to $500 \mathrm{IU} / \mathrm{L}$ indicated moderate DILI, and AST/ALT levels exceeding $500 \mathrm{IU} / \mathrm{L}$ were considered to indicate severe DILI. A baseline liver function test (LFT) abnormality was defined as AST or ALT over $40 \mathrm{IU} / \mathrm{L}$. Alcohol consumption was defined as an intake of more than $30 \mathrm{~g} /$ day of alcohol for males and $20 \mathrm{~g} /$ day for females [25].

\section{Anti-tuberculosis treatment}

In South Korea, treatment of TB is based on the $\mathrm{Na}$ tional Tuberculosis Guidelines [26]. They are nearly identical to American and World Health Organization (WHO) guidelines $[1,27]$. The recommended treatment is a 6 month regimen consisting of 2 months of INH, RFP, EMB, and PZA, followed by 4 months of INH and RFP. Most patients received daily drugs including INH (300 mg), RFP (450 $600 \mathrm{mg}$ ), EMB (800 $1200 \mathrm{mg}$ ), and PZA (1,500 mg). After patients develop DILI, additional modes of anti-TB management are used. Patients with DILI are managed in one of two ways based on the physician's judgment and treatment guidelines [26]: (1) cease the anti-TB treatment and restart treatment when liver transaminase levels fall to less than two times the upper limit of normal, or (2) cease the anti-TB treatment and restart the alternative treatment with nonhepatotoxic drugs or cease the anti-TB treatment and do not restart treatment.

\section{Statistical analysis}

SPSS (version 21.0; IBM SPSS statistics) was used for statistical analysis. Continuous variables were compared using the Mann-Whitney $U$ tests. Categorical variables were compared using Fisher's exact test and the chisquare test. The cumulative incidences of the control, $\mathrm{HBV}, \mathrm{HCV}$, and $\mathrm{HBV}+\mathrm{HCV}$ groups were analyzed using Kaplan-Meier curve and comparison of the differences of incidence was performed using the log-rank test. The 
association between DILI and the presence of HBV, $\mathrm{HCV}, \mathrm{CVH}$, or total patients was evaluated by Cox regression analysis. The risk was expressed by calculating the hazards ratio (HR) and $95 \%$ confidential interval (CI). P-values under 0.05 were considered statistically significant.

\section{Results}

\section{Patient characteristics}

A total of 379 patients were enrolled in this study. Baseline characteristics of each group are presented in Table 1. There were no significant differences in sex, other malignancies, alcohol ingestion, extrapulmonary TB, BMI, or chronic kidney disease between groups. The control group was significant older than the HBV group. The rate of use of PZA was lower in the HBV group. Incidences of hepatocellular carcinoma and liver cirrhosis were higher in the $\mathrm{CVH}$ patients. Baseline LFT abnormalities were more common in $\mathrm{CVH}$ patients.

\section{Incidence of hepatotoxicity}

In total patients who received anti-TB treatment, DILI occurred in $13.7 \%$ (52/379). The incidence of total hepatotoxicity (TLI + DILI) was higher in the HBV (34.9\%, $p=0.008)$, $\mathrm{HCV}(53.6 \%, p=0.001)$, and $\mathrm{HBV}+\mathrm{HCV}$ groups $(100 \%, p=0.002)$ than in the control group (20.7\%). In Table 2, it was shown that the HBV (21.7\%, $p=0.010)$ and HCV groups $(22.0 \%, p=0.040)$ developed higher TLI than the control group $(10.8 \%)$. The incidence of DILI was significantly higher in the $\mathrm{HCV}$
(31.7 \%, $\mathrm{p}<0.001)$ and $\mathrm{HBV}+\mathrm{HCV}$ groups $(75.0 \%, \mathrm{p}=$ 0.002 ) compared to the control group (10.0\%), but not for the HBV group $(13.3 \%, p=0.400)$. There were no significant differences in the frequencies of severe DILI in patients in the $\mathrm{HBV}, \mathrm{HCV}, \mathrm{HBV}+\mathrm{HCV}$, and control groups. In Kaplan-Meier analysis for the development of DILI, the incidence of DILI in the HCV $(\mathrm{p}=0.001)$ and HBV $+\mathrm{HCV}$ groups $(\mathrm{p}=0.001)$ were significantly higher than that of the control group, but not for the HBV group ( $\mathrm{p}=0.521)$ (Fig. 1).

\section{Risk factors associated with drug-induced liver injury}

In Table 3, we analyzed the risk factors of DILI in the subject population with anti-TB treatment by Cox regression analysis. In univariate analysis, HCV infection, $\mathrm{HBV}+\mathrm{HCV}$ co-infection, age, HCC, and baseline LFT abnormality were significant factors for DILI. In multivariate analysis, $\mathrm{HCV}$ infection $(\mathrm{HR}=2.623,95 \% \mathrm{CI}$ : 1.289-5.338, $p=0.008), \mathrm{HBV}+\mathrm{HCV}$ co-infection $(\mathrm{HR}=$ 9.401, $95 \% \mathrm{CI}=2.691-32.841, p<0.001)$, age $(\mathrm{HR}=$ $1.034,95 \% \mathrm{CI}=1.013-1.054, p=0.001)$, and baseline liver function abnormality $(\mathrm{HR}=2.331,95 \% \mathrm{CI}=1.238$ 4.390, $p=0.009$ ) were independent risk factors for DILI.

We performed subgroup analysis to identify risk factors in each viral hepatitis group. In $\mathrm{CVH}$ patients, age $(\mathrm{HR}=1.039,95 \% \mathrm{CI}=1.009-1.070, \mathrm{p}=0.011)$ and baseline LFT abnormality $(\mathrm{HR}=4.601,95 \% \mathrm{CI}=2.017$ $10.496, p \leq 0.001)$ were independent risk factors for the development of DILI (Table 4). In the HBV group, baseline LFT abnormality $(\mathrm{HR}=8.643,95 \% \mathrm{CI}=1.598$ -

Table 1 Baseline characteristics of all patients and chronic viral hepatitis patients

\begin{tabular}{|c|c|c|c|c|}
\hline & \multirow{2}{*}{$\begin{array}{l}\text { Control, } \\
\text { non-CVH } \\
(n=251)\end{array}$} & \multicolumn{3}{|l|}{$\mathrm{CVH}$} \\
\hline & & $\operatorname{HBV}(n=83)$ & $\mathrm{HCV}(n=41)$ & $\mathrm{HBV}+\mathrm{HCV}(n=4)$ \\
\hline Age, years & $59.3 \pm 17.3$ & $50.0 \pm 15.1^{a}$ & $59.9 \pm 14.9$ & $54.3 \pm 9.5$ \\
\hline Sex, female & $155(61.8)$ & $61(73.5)$ & $27(65.9)$ & $4(100)$ \\
\hline Use of PZA & $235(93.6)$ & $68(81.9)^{a}$ & $36(87.8)$ & $3(75.0)$ \\
\hline DM & $49(19.5)$ & $18(21.7)$ & $17(41.5)^{a}$ & $2(50.0)$ \\
\hline $\mathrm{HCC}$ & $1(0.4)$ & $7(8.4)^{a}$ & $2(4.9)$ & $0(0)$ \\
\hline Other malignancy & $42(16.7)$ & $8(9.8)$ & $2(4.9)$ & $0(0)$ \\
\hline Alcohol ingestion ${ }^{\mathrm{b}}$ & $42(16.7)$ & $9(10.8)$ & $7(17.1)$ & $1(25)$ \\
\hline Extrapulomary TB & $72(28.7)$ & $24(28.9)$ & $8(19.5)$ & $0(0)$ \\
\hline Past TB history & $30(12.0)$ & $19(22.9)^{\mathrm{a}}$ & $7(17.1)$ & $2(50)$ \\
\hline $\mathrm{BMI}>25 \mathrm{~kg} / \mathrm{m}^{2}$ & $37(16.5)$ & $8(10.3)$ & $6(15.4)$ & $0(0)$ \\
\hline Liver cirrhosis & $3(1.2)$ & $21(25.3)^{a}$ & $4(9.8)^{a}$ & $2(50)^{a}$ \\
\hline CKD & $13(5.2)$ & $3(3.6)$ & $2(4.9)$ & $0(0)$ \\
\hline Baseline LFT abnormality ${ }^{c}$ & $27(10.8)$ & $21(25.3)^{a}$ & $15(36.6)^{a}$ & $2(50)$ \\
\hline
\end{tabular}

Data are presented as mean \pm standard deviation for continuous data and number (\%) for categorical data. $\mathrm{HBV}$ : hepatitis $\mathrm{B}$ virus, $\mathrm{HCV}$ : hepatitis $\mathrm{C}$ virus, $\mathrm{BMI}$ : body mass index, LFT: liver function test, DM: diabetes mellitus, HCC: Hepatocellular carcinoma, TB: tuberculosis, CKD: Chronic kidney disease, PZA: pyrazinamide ${ }^{a} p$-value $<0.05$ compared to control group using Fisher's exact test or Mann-Whitney $U$ test.

${ }^{\mathrm{b}}$ Alcohol ingestion defined as consuming $30 \mathrm{~g} /$ day or more for males and $20 \mathrm{~g} /$ day or more for females.

${ }^{\mathrm{c}}$ Baseline liver function abnormality was defined as aspartate aminotransferase or alanine aminotransferase over $40 \mathrm{IU} / \mathrm{L}$. 
Table 2 Incidence of transient liver function impairment (TLI) and drug-induced liver injury (DILI) during anti-tuberculous treatment in different patient groups

\begin{tabular}{llllllll}
\hline & Control $(n=251)$ & HBV $(n=83)$ & $P$-value* & HCV $(n=41)$ & $P$-valuet & HBV+HCV $(n=4)$ & $P$-value $\neq$ \\
\hline TLI & $27(10.8)$ & $18(21.7)$ & 0.010 & $9(22.0)$ & 0.040 & $1(25.0)$ & $3(75.0)$ \\
DILI & $25(10.0)$ & $11(13.3)$ & 0.400 & $13(31.7)$ & $<0.001$ & $2(50.0)$ \\
Mild & $12(4.8)$ & $2(2.4)$ & & $7(17.1)$ & & $1(25.0)$ \\
Moderate & $8(3.2)$ & $6(7.2)$ & & $5(12.2)$ & & 0.002 \\
Severe & $5(2.0)$ & $3(3.6)$ & & $1(2.4)$ & & $0(0)$ \\
\hline
\end{tabular}

HBV: hepatitis B virus, HCV: hepatitis C virus

*P-value: Control vs. HBV group

†P-value: Control vs. HCV group

$\ddagger P$-value: Control vs. $\mathrm{HBV}+\mathrm{HCV}$ group

46.748, $p=0.012)$, diabetes $(\mathrm{HR}=8.819,95 \% \mathrm{CI}=1.228$ 63.352, $p=0.030)$, and HBV DNA $\geq 2000 \mathrm{IU} / \mathrm{ml}(\mathrm{HR}=$ 5.140, $95 \% \mathrm{CI}=1.150-22.978, p=0.032)$ were predictors for the development of DILI. In the HCV group, age $(\mathrm{HR}=1.091,95 \% \mathrm{CI}=1.014-1.173, p=0.019)$ and baseline LFT abnormality $(\mathrm{HR}=14.889,95 \% \mathrm{CI}=1.709$ $129.748, p=0.014$ ) were significant risk factors of DILI, but detection of HCV RNA was not a significant risk factor. High HBV DNA level $(\geq 2,000 \mathrm{IU} / \mathrm{ml})$ was an independent risk factor for DILI in the HBV group. HCV RNA PCR and HCV genotype were checked in only some of the patients $(n=29$ and $n=14)$. However, the detection of HCV RNA was not significant factor for DILI in the HCV group.

Onset time of drug-induced hepatitis, modes of management and recovery time

There was no significant difference in mean onset time of DILI in patients with and without CVH $(83.3 \pm 77$ days

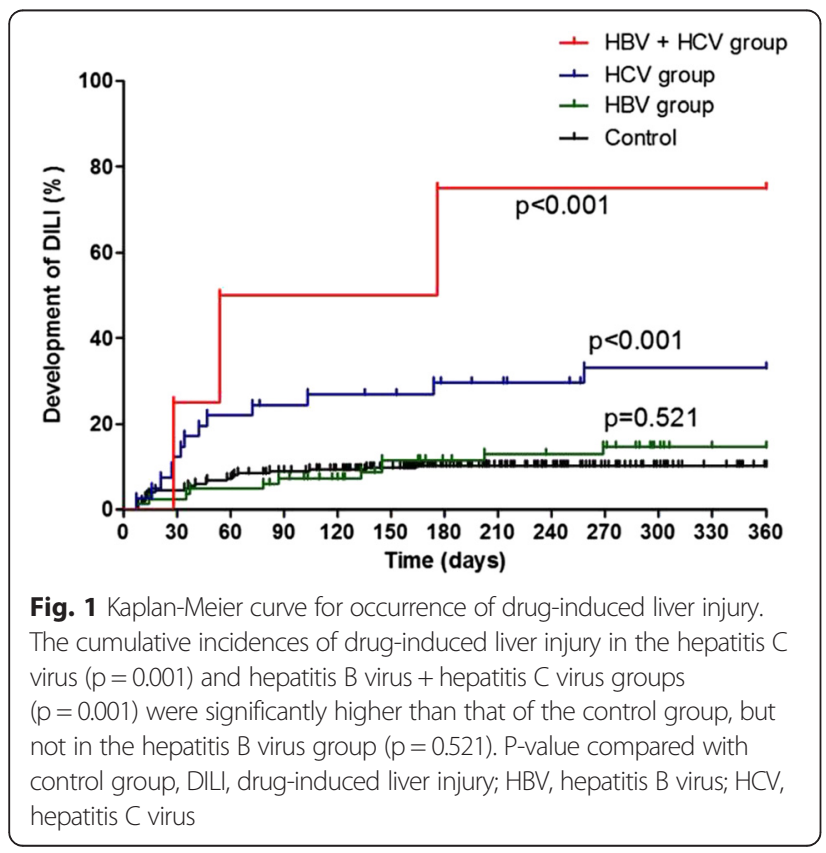

and $43.9 \pm 41$ days, $\mathrm{p}=0.056)$. Among the 52 patients who developed DILI, 9/25 (36.0 \%) of the control group and 3/27 (11.1\%) of CVH patients developed DILI within 2 weeks, which was statistically significant $(p=0.033$, data not shown). There was no statistical significance between modes of management after the development of DILI between the control and $\mathrm{CVH}$ groups. Among 52 patients with DILI, 12/25 (48 \%) and 11/27 (40.7\%) of patients successfully completed treatment with first-line drugs in the groups with and without $\mathrm{CVH}$, respectively $(p=0.509$, data not shown). The recovery time after the onset of DILI was longer in the HBV group than the control group, but not in the $\mathrm{HCV}$ and $\mathrm{HBV}+\mathrm{HCV}$ coinfection group (Fig. 2).

\section{Discussion}

In this study, DILI occurred in $13.7 \%$ of total patients who received anti-TB treatment. It was found that HCV infection and HBV + HCV co-infection were independent risk factors for DILI. However, HBV infection was not a risk factor for DILI. The incidence of DILI was similar in patients with HBV infections without the presence of viral hepatitis. However, TLI was significantly higher in HBV-infected patients than in patients without viral hepatitis.

In previous studies $[14,16,17]$, the incidence of DILI in HBV-infected patients was $7 \%$ to $12 \%$. The incidence of DILI in $\mathrm{HCV}$-infected patients was $9 \%$ to $30 \%[12-14,16,18]$. In our study, the incidence of anti-TB DILI in the control group was $10.0 \%$. In $\mathrm{CVH}$ patients, the incidence of DILI was $13.3 \%$, $31.7 \%$, and $75.0 \%$ in the HBV, HCV, and $\mathrm{HBV}+$ $\mathrm{HCV}$ groups, respectively. Compared to the control group, the incidence of DILI was significantly higher in the HCV and HBV + HCV groups, but not in the HBV group. However, when considering TLI in addition to DILI, the incidence was also statistically significant in the HBV group. There were 4 patients in our subject population that had both HBV and 
Table 3 Cox regression analysis of risk factors for drug-induced liver injury in all patients

\begin{tabular}{|c|c|c|c|c|}
\hline & \multicolumn{2}{|l|}{ Univariate analysis } & \multicolumn{2}{|l|}{ Multivariate analysis } \\
\hline & $\mathrm{HR}(95 \% \mathrm{Cl})$ & $P$-value & $\mathrm{HR}(95 \% \mathrm{Cl})$ & $P$-value \\
\hline Control & Reference & & & \\
\hline HBV & $1.291(0.635-2.624)$ & 0.481 & $1.321(0.612-2.850)$ & 0.479 \\
\hline $\mathrm{HCV}$ & $3.425(1.752-6.697)$ & $<0.001$ & $2.623(1.289-5.338)$ & 0.008 \\
\hline $\mathrm{HBV}+\mathrm{HCV}$ & $9.273(2.793-30.788)$ & $<0.001$ & $9.401(2.691-32.841)$ & $<0.001$ \\
\hline Age, per year & $1.025(1.007-1.043)$ & 0.005 & $1.034(1.013-1.054)$ & 0.001 \\
\hline $\mathrm{HCC}$ & $3.361(1.212-9.322)$ & 0.020 & $1.7900 .598-5.356)$ & 0.298 \\
\hline Baseline LFTAbnormality ${ }^{a}$ & $2.702(1.526-4.784)$ & 0.001 & $2.331(1.238-4.390)$ & 0.009 \\
\hline
\end{tabular}

HBV: hepatitis B virus, HCV: hepatitis C virus, HCC: Hepatocellular carcinoma, HR: hazards ratio, Cl: confidential interval, BMI: body mass index (kg/m²), LFT: liver function test

${ }^{a}$ Baseline LFT Abnormality: aspartate aminotransferase $>40 I U / L$ or alanine aminotransferase $>40 I U / L$

$\mathrm{HCV}$ infection. In this group, one patient showed TLI, while the remaining three developed DILI.

In some previous studies, it has been documented that HBV infections increase the risk for DILI. In Hong Kong, Wong et al. found that HBV infections were a significant risk factor for liver dysfunction. However, that study did not classified TLI and DILI, and only defined liver dysfunction as an increase in ALT levels to 1.5 times above the UNL [11]. If we applied that definition to our study, we would find a similar result: a significant incidence of any liver function impairment. In previous studies applied same definition of DILI $[14,16]$, the incidence of DILI in HBV patients were not significantly increased compared to normal control groups. In the HBV group, high HBV DNA level $(\geq 2,000 \mathrm{IU} / \mathrm{ml})$ is an independent risk factor for DILI $(H R=5.140$, Table 4$)$. In a previous study [28], it was recommended that using an antiviral agent to decrease the viral load to prevent the development of liver dysfunction. In the present study, among the 83 patients in HBV group, 16 patients were medicated with an antiviral agent, while 67 patients were not. The administration of an antiviral agent did not decrease the risk of DILI (data not shown).

In the $\mathrm{HCV}$ group, there was no statistical significance regarding the detection of $\mathrm{HCV}$ RNA, an $\mathrm{HCV}$ genotype. A previous study in Taiwan [24], found that a high initial $\mathrm{HBV} / \mathrm{HCV}$ viral load was a significant risk factor for DILI. In another study, the detection of HCV viral load and HCV genotype were not significant predictors of DILI [12]. The mechanism accounting for the higher incidence of DILI in the HCV group than in the HBV group is not known yet. In a previous study, Wedemeyer et al. showed HCV core protein alters lipid metabolism, contributing to the development of hepatic steatosis. Hepatic steatosis may trigger hepatocyte apoptosis, which facilitates inflammation and fibrosis [29]. Other studies have explained that a high baseline viral load more frequently leads to the development of DILI [24]. A pro-inflammatory environment induced by actively replicating the hepatitis virus may alter the detoxication process and increase drug toxicity [30]. Although, we did not find any associations with BMI and

Table 4 Cox regression analysis of risk factors for anti-tuberculosis drug-induced liver injury in chronic viral hepatitis, chronic hepatitis $B$, and chronic hepatitis C

\begin{tabular}{|c|c|c|c|}
\hline \multirow[b]{2}{*}{ Variables } & \multicolumn{3}{|c|}{ Multivariate analysis: hazard ratio (95 \% confidential interval) } \\
\hline & $\mathrm{CVH}(n=128)$ & $\operatorname{HBV}(n=83)$ & $\mathrm{HCV}(n=41)$ \\
\hline Age & $1.039(1.009-1.070)$ & $0.990(0.933-1.051)$ & $1.091(1.014-1.173)$ \\
\hline Sex (female) & & $5.010(0.518-48.478)$ & $0.312(0.059-1.639)$ \\
\hline DM & $2.064(0.879-4.847)$ & $8.819(1.228-63.352)$ & \\
\hline $\mathrm{HCC}$ & $0.866(0.253-2.966)$ & & $1.977(0.309-12.632)$ \\
\hline Liver cirrhosis & & & $0.190(0.026-1.362)$ \\
\hline Baseline LFT abnormality ${ }^{\mathrm{a}}$ & $4.601(2.017-10.496)$ & $8.643(1.598-46.748)$ & $14.889(1.709-129.748)$ \\
\hline HBV DNA $\geq 2000 \mathrm{IU} / \mathrm{ml}^{\mathrm{b}}$ & & $5.140(1.150-22.978)$ & \\
\hline HCV RNA detected ${ }^{c}$ & & & $0.361(0.026 \sim 5.051)$ \\
\hline
\end{tabular}

DM: diabetes mellitus, HCC: Hepatocellular carcinoma, LFT: liver function test, HBV: hepatitis B virus, HCV: hepatitis C virus

${ }^{a}$ Baseline LFT Abnormality: aspartate aminotransferase $>40 I U / L$ or alanine aminotransferase $>40 I U / L$

${ }^{\mathrm{b}}$ Among available data in 59 patients, 21 patients had high HBV DNA ( $\geq 2000 \mathrm{IU} / \mathrm{ml}$ )

'HCV RNA available $(n=29)$, detected $(n=24)$, not detected $(n=5)$ 


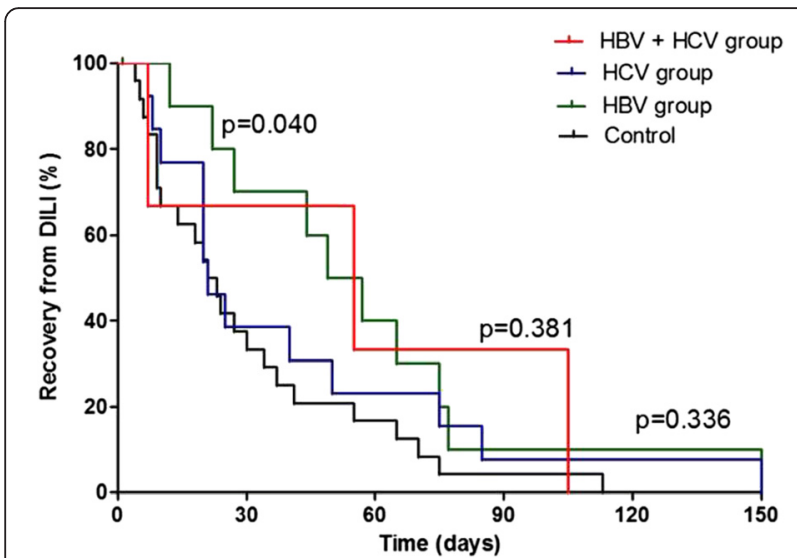

Fig. 2 Kaplan-Meier curve for recovery from drug-induced liver injury. The recovery rate of drug-induced liver injury in hepatitis B virus $(p=0.040)$ was significantly higher in the early period than that of the control group, but not in the hepatitis $C$ virus $(p=0.036)$ and hepatitis $B$ virus + hepatitis $C$ virus groups $(p=0.381)$. P-value compared with control group. DILI, drug-induced liver injury; HBV, hepatitis B virus; HCV, hepatitis $C$ virus

hepatotoxcity, there are some studies indicating low BMI as a risk factor [31]. Further study is needed about the interaction of CVH and high incidence of DILI.

Previous studies have reported that DILI usually occurs within 2 months of the anti-TB treatment [32]. Liu et al. reported that TLI occurred later in CVH patients, but not for DILI [16]. In present study, DILI was more common in the $\mathrm{CVH}$ group than the control group after 2 weeks of treatment. In addition, there was no difference in the modes of treatment management of DILI between the control and $\mathrm{CVH}$ groups. In previous studies [16-18], the severity of DILI was not significantly different in the control and $\mathrm{CVH}$ groups. In another previous study [14], both the HBV and HCV groups had longer durations of AST/ALT elevation compared to the control group. In this study, the recovery time after the onset of DILI was longer in the HBV group than in the control group, but not in the $\mathrm{HCV}$ and $\mathrm{HBV}+\mathrm{HCV}$ coinfection groups.

This study has some limitations. First, because of its retrospective nature, the study may provide inaccurate information about alcohol intake or herbal medication. Second, there was a lack of information about the hepatitis virus in $\mathrm{CVH}$ patients, HBV DNA and HCV RNA viral load, HCV genotype, etc. Third, this was a single-center study with a relatively small sample size, especially $\mathrm{HBV}+\mathrm{HCV}$ co-infection group. Forth, there were so many baseline differences between the 2 main patient groups and the control group such that outcomes would be predicted to be different on this basis alone. Further prospective study with more patients is needed to gleam more detailed information about the hepatitis virus.

\section{Conclusion}

$\mathrm{HCV}$ infection and $\mathrm{HBV}+\mathrm{HCV}$ co-infection were associated with anti-TB treatment-induced hepatotoxicity. HBV infection was only associated with TLI. In the total patient population receiving anti-TB treatment, the independent risk factors for DILI were $\mathrm{HCV}$ with or without HBV infection, age, and baseline liver function abnormality. It is recommended to carefully monitor for DILI in patients with $\mathrm{HCV}$ or $\mathrm{HBV}+\mathrm{HCV}$ co-infections, old age, and abnormal baseline LFTs.

\section{Abbreviations}

TB: Tuberculosis; TLI: Transient liver function impairment, DIH, drug induced hepatitis; HBV: Hepatitis B virus; HCV: Hepatitis C virus; LFT: Liver function test; BMI: Body mass index; HR: Hazards ratio; Cl: Confidence interval; $\mathrm{CVH}$ : Chronic viral hepatitis.

\section{Competing interest}

The authors declare that they have no competing interests

\section{Author's contributions}

WSK and SSL participated in the study design and concept, performed the statistical analysis and participated in data interpretation, and participated in manuscript writing. CML, HongJK, and CYH participated in data collection. HyunJK and THK performed the statistical analysis and participated in data interpretation. WTJ, OJL, and HCC participated in the study design and concept. JWH and HSY participated in data collection and performed the statistical analysis and participated in data interpretation. All authors read and appproved the final manuscript.

\section{Acknowledgments}

We are grateful to the devoted our collaborators and research coordinators (Jeong Mi Lee, Hye Won Oh, and Ra Ri Cha)

\section{Financial support}

There was no financial support in this study

\section{Author details}

'Department of Internal Medicine, Gyeongsang National University Hospital, Gyeongsang National University School of Medicine, Gangnam-ro 79, Jinju, Gyeognam 660-702, South Korea. '2Department of Internal Medicine, Samsung Changwon Hospital, Sungkyunkwan University School of Medicine, Palyong-ro, 158, MasanHoiwon-gu, Chang-Won, Republic of Korea.

Received: 18 June 2015 Accepted: 12 January 2016

Published online: 01 February 2016

\section{References}

1. Blumberg HM, Burman WJ, Chaisson RE, Daley CL, Etkind SC, Friedman LN, et al. American Thoracic Society/Centers for Disease Control and Prevention/Infectious Diseases Society of America: treatment of tuberculosis. Am J Respir Crit Care Med. 2003;167(4):603-62.

2. Sharifzadeh M, Rasoulinejad M, Valipour F, Nouraie M, Vaziri S. Evaluation of patient-related factors associated with causality, preventability, predictability and severity of hepatotoxicity during antituberculosis [correction of antituberclosis] treatment. Pharmacol Res. 2005;51(4):353-8.

3. Sharma SK, Balamurugan A, Saha PK, Pandey RM, Mehra NK. Evaluation of clinical and immunogenetic risk factors for the development of hepatotoxicity during antituberculosis treatment. Am J Respir Crit Care Med. 2002;166(7):916-9.

4. van Hest R, Baars H, Kik S, van Gerven P, Trompenaars MC, Kalisvaart N, et al Hepatotoxicity of rifampin-pyrazinamide and isoniazid preventive therapy and tuberculosis treatment. Clin Infect Dis. 2004;39(4):488-96.

5. Tost JR, Vidal R, Cayla J, Diaz-Cabanela D, Jimenez A, Broquetas JM, et al. Severe hepatotoxicity due to anti-tuberculosis drugs in Spain. Int J Tuberc Lung Dis. 2005;9(5):534-40. 
6. Singanayagam A, Sridhar S, Dhariwal J, Abdel-Aziz D, Munro K, Connell DW, et al. A comparison between two strategies for monitoring hepatic function during antituberculous therapy. Am J Respir Crit Care Med. 2012;185(6):653-9.

7. Saukkonen JJ, Cohn DL, Jasmer RM, Schenker S, Jereb JA, Nolan CM, et al. An official ATS statement: hepatotoxicity of antituberculosis therapy. Am J Respir Crit Care Med. 2006:174(8):935-52.

8. $\quad$ Dossing M, Wilcke JT, Askgaard DS, Nybo B. Liver injury during antituberculosis treatment: an 11-year study. Tuber Lung Dis. 1996;77(4): 335-40

9. Pande JN, Singh SP, Khilnani GC, Khilnani S, Tandon RK. Risk factors for hepatotoxicity from antituberculosis drugs: a case-control study. Thorax. 1996:51(2):132-6.

10. Fernandez-Villar A, Sopena B, Fernandez-Villar J, Vazquez-Gallardo R, Ulloa F, Leiro $V$, et al. The influence of risk factors on the severity of anti-tuberculosis drug-induced hepatotoxicity. Int J Tuberc Lung Dis. 2004;8(12):1499-505.

11. Wong WM, Wu PC, Yuen MF, Cheng CC, Yew WW, Wong PC, et al. Antituberculosis Drug-Related Liver Dysfunction in Chronic Hepatitis B Infection. Hepatology. 2000;31:201-6.

12. Lomtadze N, Kupreishvili L, Salakaia A, Vashakidze S, Sharvadze L, Kempker $R R$, et al. Hepatitis C virus co-infection increases the risk of anti-tuberculosis drug-induced hepatotoxicity among patients with pulmonary tuberculosis. PLoS One. 2013;8(12):e83892.

13. Ungo JR, Jones D, Ashkin D, Hollender ES, Bernstein D, Albanese AP, et al. Antituberculosis drug-induced hepatotoxicity. The role of hepatitis $C$ virus and the human immunodeficiency virus. Am J Respir Crit Care Med. 1998; 157(6 Pt 1):1871-6.

14. Devarbhavi $H$, Singh R, Patil M, Sheth K, Adarsh CK, Balaraju G. Outcome and determinants of mortality in 269 patients with combination anti-tuberculosis drug-induced liver injury. J Gastroenterol Hepatol. 2013;28(1):161-7.

15. Fernandez-Villar A, Sopena B, Garcia J, Gimena B, Ulloa F, Botana M, et al. Hepatitis $C$ virus RNA in serum as a risk factor for isoniazid hepatotoxicity. Infection. 2007;35(4):295-7.

16. Liu YM, Cheng YJ, Li YL, Liu CE, Hsu WH. Antituberculosis treatment and hepatotoxicity in patients with chronic viral hepatitis. Lung. 2014; 192(1):205-10.

17. Lee B-H, Koh W-J, Choi M-S, Suh G-Y, Chung M-P, Kim H-j, et al. Inactive HBsAg carrier state and hepatotoxicity during antiTB chemotherapy. Chest. 2005;127(4):1304-11.

18. Kwon YS, Koh WJ, Suh GY, Chung MP, Kim H, Kwon OJ. Hepatitis C virus infection and hepatotoxicity during antituberculosis chemotherapy. Chest. 2007;131(3):803-8.

19. S-J HWANG, J-C WU, C-N LEE, F-S YEN, C-L LU, T-P LIN, et al. A prospective clinical study of isoniazid-rifampicin-pyrazinamideinduced liver injury in an area endemic for hepatitis B. J Gastroenterol Hepatol. 1997;12:87-91.

20. de Castro L, Do Brasil PE, Monteiro TP, Rolla VC. Can hepatitis B virus infection predict tuberculosis treatment liver toxicity? Development of a preliminary prediction rule. Int J Tuberc Lung Dis. 2010;14(3):332-40.

21. Un-yeoung G, Hyun-jin S, Yeon-kyeng L, Hyosoon Y, Yoon-sung P, Haeyoung $\mathrm{K}$, et al. Annual report on the notified tuberculosis in korea. In: Prevention KCfDC, editor. Korea Centers for Disease Control \& Prevention: YANG Byung-guk. 2012. p. 12.

22. Park NH, Chung $\mathrm{YH}$, Lee HS. Impacts of vaccination on hepatitis B viral infections in Korea over a 25-year period. Intervirology. 2010;53(1):20-8.

23. The Korean Association for the Study of the L. KASL clinical practice guidelines: Management of Hepatitis C. Clin Mol Hepatol. 2014;20(2):89-136.

24. Wang CW, Lin HY, Shin SJ, Yu ML, Lin ZY, Dai CY, et al. The PNPLA3 $1148 \mathrm{M}$ polymorphism is associated with insulin resistance and nonalcoholic fatty liver disease in a normoglycaemic population. Liver Int. 2011;31(9):1326-31.

25. Tarantino G, Saldalamacchia G, Conca P, Arena A. Non-alcoholic fatty liver disease: further expression of the metabolic syndrome. J Gastroenterol Hepatol. 2007;22(3):293-303.

26. Moon H, Lee J. Korean Guidelines for Tuberculosis. Korea: Joint Committee for the Development of Korean Guidelines for Tuberculosis; 2011.

27. WHO: Treatment of tuberculosis guidelines, 4th ed. Geneva, World Health Organization, 2010 (WHO/HTM/STB/2009.420). Available: http://whqlibdoc. who.int/publications/2010/9789241547833_eng.pdf.

28. Dhiman RK, Saraswat VA, Rajekar H, Reddy C, Chawla YK. A Guide to the Management of Tuberculosis in Patients with Chronic Liver Disease. J Clin Exp Hepatol. 2012;2(3):260-70.
29. Wedemeyer I, Bechmann LP, Odenthal M, Jochum C, Marquitan G, Drebber $U$, et al. Adiponectin inhibits steatotic CD95/Fas up-regulation by hepatocytes: therapeutic implications for hepatitis C. J Hepatol. 2009;50(1): $140-9$.

30. Schenker S, Martin RR, Hoyumpa AM. Antecedent liver disease and drug toxicity. J Hepatol. 1999;31(6):1098-105.

31. Tostmann A, Boeree MJ, Aarnoutse RE, de Lange WC, van der Ven AJ, Dekhuijzen R. Antituberculosis drug-induced hepatotoxicity: concise up-todate review. J Gastroenterol Hepatol. 2008;23(2):192-202.

32. Sun H-Y, Chen I-L, Gau C-S, Chang S-C, Luh K-T. A Prospective Study of Hepatitis During Antituberculous Treatment in Taiwanese Patients and a Review of the Literature. J Formos Med Assoc. 2009;108(2):102-11.

\section{Submit your next manuscript to BioMed Central and we will help you at every step:}

- We accept pre-submission inquiries

- Our selector tool helps you to find the most relevant journal

- We provide round the clock customer support

- Convenient online submission

- Thorough peer review

- Inclusion in PubMed and all major indexing services

- Maximum visibility for your research

Submit your manuscript at www.biomedcentral.com/submit

) Biomed Central 